\title{
Mining induced strata movement and roof behavior in underground coal mine
}

\author{
Tao Xu • Tian-hong Yang • Chong-feng Chen $\cdot$ Hong-lei Liu • \\ Qing-lei Yu
}

Received: 1 July 2015/Accepted: 7 September 2015/Published online: 18 September 2015

(C) Springer International Publishing Switzerland 2015

\begin{abstract}
The fracturing and caving process of key strata in overburden strata and the distribution law of abutment stress over key strata and immediate roof are investigated and the effect of the rupture of key strata on abutment stress in coal rib and the subsidence of earth's surface are also analyzed. The simulated results show that the abutment stress over key strata and immediate roof are not uniformly distributed. The rupture of key strata has a great impact on the abutment stress in coal rib, i.e., the abutment stress is much high before the rupture of key strata and reaches to the maximum on fracturing and then decreases sharply after fracturing and the peak abutment stress moves away from working face into coal seam. In addition, the rupture of key strata has also impact on
\end{abstract}

T. Xu ( $₫) \cdot$ T. Yang $\cdot$ C. Chen $\cdot$ H. Liu $\cdot$ Q. Yu MOE Key Laboratory of Safe Mining of Deep Metal Mines, Northeastern University, Shenyang 110819, China e-mail: neuxutao@126.com

T. Yang

e-mail: yangtianhong@mail.neu.edu.cn

C. Chen

e-mail: 871330060@qq.com

H. Liu

e-mail: liuhonglei@mail.neu.edu.cn

Q. $\mathrm{Yu}$

e-mail: yuqinglei@mail.neu.edu.cn

T. Xu · T. Yang $\cdot$ C. Chen $\cdot$ H. Liu $\cdot$ Q. Yu Center for Rock Instability and Seismicity Research, Northeastern University, Shenyang 110819, China the subsidence of the earth's surface. The subsidence ratio is basically stable before fracturing and increases remarkably after fracturing and gradually becomes stable as mining.

Keywords Strata movement · Abutment stress · Key strata $\cdot$ Longwall mining

\section{Introduction}

The extraction and use of coal resources remarkably benefits human being but also causes a series of adverse impacts on the environment that challenge all of the coal mining countries. Coal extraction commonly causes strata movement and land subsidence that then leads to mining hazards such as ground water in-rush, rock burst and damages to buildings or structures on the surface, as well as pollution of the environment. For many years, longwall mining is one of the common mining methods for extracting coal in various thicknesses of coal seams and is much more effective, productive and safer than any other mining methods. The productivity of longwall mining is potentially high because it is basically a continuous operation requiring fewer workers and allowing a high production rate to be sustained. A longwall face is generally between 200 and $400 \mathrm{~m}$ long and the full thickness of the seam is extracted by a coal shearer. After advance of the face the roof located behind the 
support becomes unsupported, loose and even caved. In longwall mining, the primary objective is to design coal pillars that are left in place to control mine stability and surface subsidence and, hence, to prevent damage to surface or near-surface structures such as buildings, railways, highways, rivers and pipelines. Poor knowledge of the characteristics of strata movement due to longwall mining can create very serious ground hazards, potentially jeopardizing the safety and lives of mine personnel, as well as affecting the productivity and efficiency of a mining operation. For decades, extensive effort has been paid to study the strata movement and stress distribution law induced by mining excavation and obtain comprehensive understanding of the permeability evolution of coal seam (Chen et al. 2014; Xie et al. 2015; Yang et al. 2011a, b) and a proper design of a coal pillar (Chugh et al. 1990; Hammy and Fejes 1992; Holla 1997; Holla and Buizen 1991a; Islam et al. 2009). Holla and Buizen (1991b) performed an empirical study of the sub-surface deformation caused by retreating longwall mining and monitored the strata movement over a longwall panel and indicated that the three-joint-arch structure formed by the broken key roof stratum is monotonically unstable structure and its limit value is determined by the breaking convergence value. Moreover, the mechanism of the main roof breaking at shallow depth is due to the bifurcation instability of the roof structure. Hammy and Fejes (1992) characterized the overburden response to long wall mining in the Western United States. Yang (2010) studied the stability of nearly horizontal roof strata in shallow seam longwall mining panel. Hosseini et al. (2013) analyzed the periodic roof weighting interval in longwall mining using finite element method. Hosseini et al. (2013) studied the stress redistribution around the longwall mining panel using passive seismic velocity tomography and geo-statistical estimation. Wang et al. (2013) presented a numerical investigation on the dynamic mechanical state of a coal pillar and the assessment of the coal bump risk during extraction using the longwall mining method and the results predicted that the peak abutment stress occurs near the intersection between the mining face and the roadways at a distance of $7.5 \mathrm{~m}$ from the mining face. Suchowerska et al. (2013) studied vertical stress changes in multi-seam mining under super critical longwall panels and found that the abutment angle has a significantly greater effect on the magnitude of the relative changes in vertical stress in the strata below a pillar than the overburden depth. Ju and Xu (2013) studied the structural characteristics of key strata and strata behaviour of a fully mechanized longwall face with $7.0 \mathrm{~m}$ height chocks and proposed a calculation method of working resistance for $7.0 \mathrm{~m}$ height chocks. Shibata et al. (2014) described the applicability of the longwall mining system from final highwall and its suitable design taking the slope stability into consideration and performed a preliminary study on design of long-wall mining from final highwall at Mae Moh Lignite mine in Thailand using Flac3D.

Though extensive effort has been paid to understand the rupture and collapse of overburden strata and the abutment stress redistribution patterns above coal face and key strata and around coal pillar, there remains unclear about the dynamic mechanical state of a coal pillar and the nonlinear behavior associated with mining-related rock mechanics problems during the extraction of a longwall mining panel. A thorough understanding of in situ stress environment is essential for effective ground control during underground mining. In particular, understanding the stress field around a longwall panel and overburden strata movement law is one of the key components that enables mining engineers to predict potential failures. Thus, in this paper, the progressive damage, fracture and collapse process of rock strata, from the initiation and propagation of cracks firstly in the two heads and the middle part of strata to rupture and collapse of strata, viz., weighting, is simulated to investigate the characteristics of strata movement, surface subsidence and abutment stress distribution above coal face and key layers as mining. The work described in this paper has attempted to investigate the rupture and collapse characteristics of overburden strata and the redistribution of abutment stress patterns above coal face and key strata during the underground mining based on the geological condition of a typical longwall panel from a coal mine.

\section{Description of the model}

The theory of elastic-damage mechanics is incorporated into the model and the elastic and isotropic damage is assumed in the rock failure process analysis (abbreviated as RFPA) model. The model accounts for material heterogeneity to obtain a collective macroscopic 
behaviour different from those of the elements through a stochastic local failure stress field. There are four features distinguishing it from other numerical model: (1) by introducing heterogeneity of rock properties into the model, it can simulate non-linear deformation of a quasi-brittle behavior with an ideal brittle constitutive law for the local material, (2) by introducing degradation of material parameters after element failure, it can simulate strain-softening behavior, (3) by recording the event accounts and event rates of failed elements, the seismicities associated with the progressive failure in rock can be simulated, (4) by the setting of step caving, the advancing of mining face can be simulated.

Specifically, in the model the inhomogeneity or heterogeneity of material is incorporated to obtain a collective macroscopic behaviour different from those of the elements. There are two levels of heterogeneity in rock mass, one being the differences in properties between the rock block and the discontinuity such as joints (Wasantha et al. 2015) or fractures (NoorianBidgoli and Jing 2015; Yakovlev et al. 2010) at a macro-scale, and the other being the heterogeneity within the intact rock blocks due to differences in the randomly distributed flaws at a meso-scale. In the model, because the system was analysed at a mesoscale, the heterogeneity within the intact rock blocks due to the differences in the degree of weathering and the randomly distributed flaws at a meso-scale was taken into account. The mechanical properties such as strength and Young's modulus of the mesoscopic material elements, which are assumed to be homogeneous and isotropic, are assigned randomly from the

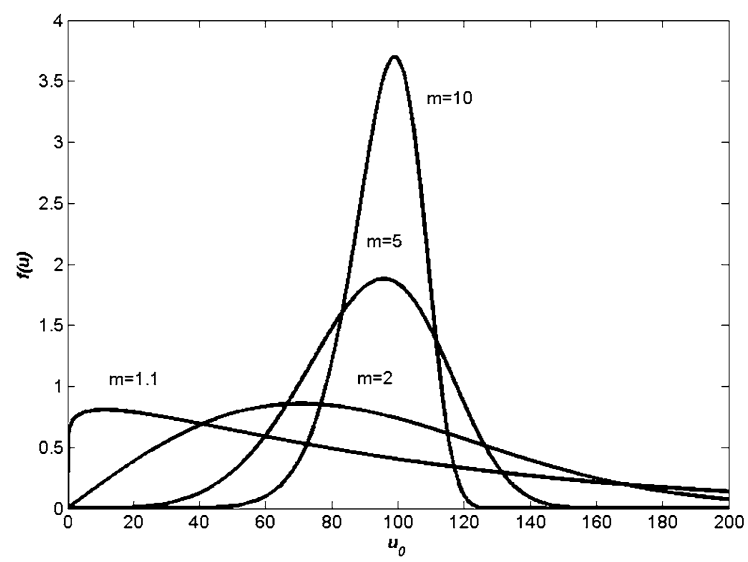

Fig. 1 Weibull distribution for element failure strength
Weibull statistical distribution (Weibull 1951) as shown in Fig. 1.

$f(u)=\frac{m}{u_{0}}\left(\frac{u}{u_{0}}\right)^{m-1} \exp \left[-\left(\frac{u}{u_{0}}\right)^{m}\right]$

where $u$ is the mechanical parameter of individual element such as failure strength or elastic modulus and $u_{0}$ is a scale parameter relative to the mechanical parameter of all elements, i.e., the mean mechanical property of the elements for the specimen $m$ is defined as the homogeneity index of the material. According to the definition, a larger $m$ implies a more homogeneous material and vice versa.

The maximum tensile strain criterion and a modified Mohr-Coulomb criterion with a tension cut-off are adopted as two damage thresholds (Brady and Brown 2004). This makes it possible to simulate the transition from distributed damage by tensile microcracking to damage where microcracks can interact, coalesce, and ultimately form a shear fault. The stressstrain relationship can be described by an elastic damage constitutive law. Continuum damage mechanics can describe the effects of progressive microcracking, void nucleation, and micro-crack growth at high stress levels using a constitutive law, by making use of a set of state variables modifying the material behaviour at the macroscopic level. Using an isotropic continuum damage formulation, the constitutive law for an isotropic and elastic material at instantaneous loading can be written as (Lemaitre and Desmorat 2005)

$\varepsilon_{i j}=\frac{1+v}{E} \sigma_{i j}-\frac{v}{E} \sigma_{k k} \delta_{i j}$.

$E=E_{0}(1-D)$

where $\varepsilon_{i j}$ is the damaged elastic strain tensor, $\sigma_{i j}$ is the stress tensor, $E$ and $E_{0}$ are the Young's modulus of the damaged and undamaged material, respectively, $D$ is the isotropic damage variable, $v$ is the Poisson's ratio and $\delta_{i j}$ is the Kronecker symbol. In the case of a uniaxial state of stress $\left(\sigma_{11} \neq 0, \sigma_{22}=\sigma_{33}=0\right)$, the constitutive relation can be rewritten in terms of the longitudinal stress and strain components only

$\sigma_{11}=E_{0}(1-D) \varepsilon_{11}$

Hence, for uniaxial loading, the constitutive law is explicitly dependent on the damage index $D$. 


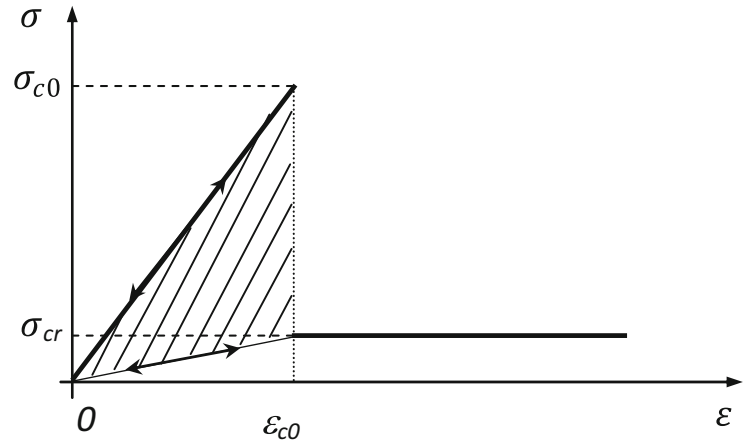

(a)

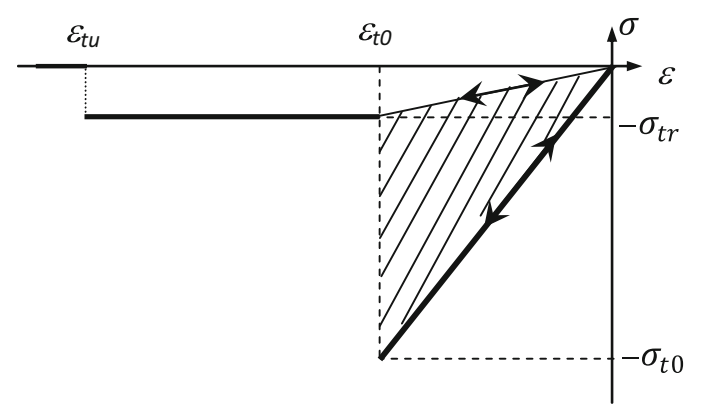

(b)

Fig. 2 Constitutive law for element in uniaxial compression (a) and uniaxial tension (b)

The model is based on progressive isotropic elastic damage. Figure 2 shows the constitutive law for an element in uniaxial compression and uniaxial tension. When the stress on an ent exceeds a damage threshold, its Young's modulus $E$ is modified according to Eq. (4). In the beginning, each element is considered to be elastic, as defined by a specific Young's modulus and Poisson's ratio. The stress-strain curve of the element is considered linear elastic with a constant residual strength until the given damage threshold is reached. The maximum tensile strain criterion and modified Mohr-Coulomb criterion with tension cutoff (Brady and Brown 2004; Jeager et al. 2007) have been selected as two damage thresholds. At any time, the tensile strain criterion is preferred since the tensile strength of rock is far lower than its compressive strength.

Specifically, when the mesoscopic element is under uniaxial tensile stress, at the beginning, the stressstrain curve is linear elastic and no permanent damage occurs. When the maximum tensile strain criterion is met for a given element, the element is damaged.
According to the constitutive law of mesoscopic elements under uniaxial tension, the damage evolution of element $D$ can be expressed as (Tang et al. 2006)

$D= \begin{cases}0 & \varepsilon<\varepsilon_{t 0} \\ 1-\frac{\sigma_{t r}}{\varepsilon E_{0}} & \varepsilon_{t 0} \leq \varepsilon<\varepsilon_{t u} \\ 1 & \varepsilon \geq \varepsilon_{t u}\end{cases}$

where $\sigma_{t r}$ is the residual uniaxial tensile strength and $\sigma_{t r}=\lambda \sigma_{t 0}$ where $\lambda$ is the residual strength coefficient and $\sigma_{t 0}$ is the uniaxial tensile strength at the elastic strain limit $\varepsilon_{t 0} . \varepsilon_{t u}$ is the ultimate tensile strain of the element. Equation (5) indicates that an element would be completely damaged when the tensile strain of the element attains this ultimate tensile strain.

Similarly, when the element is under uniaxial compression and damaged in shear mode according to the Mohr-Coulomb criterion, the damage variable $D$ can be described as follows (Tang et al. 2006)

$D= \begin{cases}0 & \varepsilon \leq \varepsilon_{c 0} \\ 1-\frac{\sigma_{c r}}{\varepsilon E_{0}} & \varepsilon>\varepsilon_{c 0}\end{cases}$

where $\sigma_{c r}$ is the residual uniaxial compressive strength and is defined as $\sigma_{c r}=\lambda \sigma_{c 0}$. In the model, it is assumed that $\sigma_{c r} / \sigma_{c 0}=\sigma_{t r} / \sigma_{t 0}=\lambda$ holds true when the mesoscopic element is in uniaxial compression or tension.

From the above derivation of the damage variable $D$ (which is generally called the damage evolution law in damage mechanics) and Eq. (4), the damaged Young's modulus of an element at different stress or strain levels can be calculated. The unloaded element keeps its original Young's modulus and strength prior to its strength threshold. That is to say, the element can always return to its original point when unloading. It must be emphasized that when damage variable $D$ is equal to 1 , Eq. (4) stipulates that the damaged Young's modulus will be zero, which would make the system of equations illposed. Therefore, a relatively small value $(1.0 \mathrm{e}-05)$ is given for the Young's modulus under this condition.

In addition, in the model a single damage event represents a micro-crack-forming event to assess the damage evolution, and the damage energy release is related to the strain energy of the element before and after its damage. Therefore, the number of damage events is counted by the number of damaged elements 
and the damage energy release can be determined from the area of shadow shown in Fig. 2. The damage energy release from an individual damaged element in uniaxial compression can be expressed as follows

$e_{f}=\frac{(\lambda-1) \sigma_{c 0}^{2}}{2 \lambda E} V_{e}$

and the cumulative damage energy can be obtained from the strain energy release of damaged elements

$\sum e_{f}=\frac{(\lambda-1) V_{e}}{2 \lambda} \sum \frac{\sigma_{c 0}^{2}}{E}$

where $E$ is the elastic modulus of the individual element, $V_{e}$ is the volume of the individual element, and $\sigma_{c 0}$ is the uniaxial failure strength of the individual element. Similarly, the damage energy release from an individual damaged element $\frac{(\lambda-1) \sigma_{t 0}^{2}}{2 \lambda E} V_{e}$ and the cumulative damage energy $\frac{(\lambda-1) V_{e}}{2 \lambda} \sum \frac{\sigma_{t 0}^{2}}{E}$ in uniaxial tension can also obtained. After each damage event, we update the damage, the stress, and the strength of each element.

Thus, the model can be used to describe the damage and fracture of heterogeneous brittle rock and the extraction or excavation of coal or rock. More details about the model can refer to the publications ( $\mathrm{Li}$ et al. 2014; Xu et al. 2006, 2012, 2013, 2014).

\section{Numerical model setup}

In this section, the model is used to investigate the characteristics of deformation and fracturing of overburden strata during the extraction of coal seam. The main mineable coal seam of the coal mine is $5 \mathrm{~m}$ thick on average and is nearly horizontal. The panel is mined using the longwall mining method. The immediate roof of the panel is composed of sandy mudstone and is approximately $5 \mathrm{~m}$ thick. The average depthof coal seam below surface is approximately $175 \mathrm{~m}$. The coal panels were planned for extraction by means of longwall mining face in the mining panel. Coal has been produced by means of longwall retreat method where a $5 \mathrm{~m}$ high longwall face was operated at the floor of the coal seam. According to the site-specific conditions, a reasonable study area of 1.5-2 times of the maximum mining area is determined. The model domain for the study area is $225 \mathrm{~m}$ in height and $350 \mathrm{~m}$ in length. The thickness of the upper coal seam

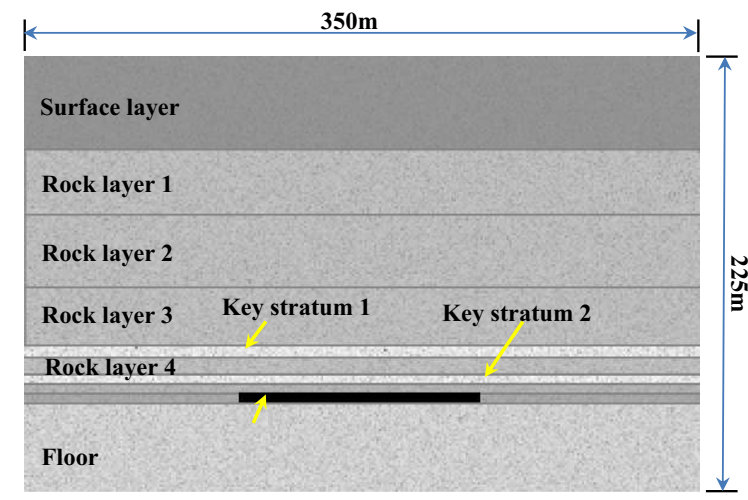

Fig. 3 Numerical model for coal mining

is $5 \mathrm{~m}$, which is located at $180 \mathrm{~m}$ below the earth surface. The numerical model discretized into 50,400 elements $(180 \times 280)$ contains a total of 10 strata based on the site-specific geological conditions as shown in Fig. 3. Considering the effect of bedding and weak plane on the failure of rock mass, it is necessary to embed some bedding plane between two contiguous strata in the model. Longwall mining method is employed and the roof is managed by caving method. The mining length of coal seam is $100 \mathrm{~m}$, with 20 steps in total, that is, $5 \mathrm{~m}$ each step. In the light of sitespecific mining conditions, it is assumed that the time interval of each step is a half day, i.e. the extraction of coal seam lasts 10 days of the whole mining process in the simulation.

In the simulation, plane strain model as shown in Fig. 1 is adopted. The elements in the numerical model are characterized by the Young's modulus (E), uniaxial compressive strength and Poisson's ratio (v). It is crucial to properly assess the properties of the surrounding rock to obtain acceptable results for numerical modeling. Therefore, the physical and mechanical properties of each geological unit must be determined. In general, the properties of the surrounding rock are determined by laboratory testing. Samples of the surrounding rock described above were obtained from exploration drilling cores and rock blocks taken directly from the coal mine. According to the available literature (Brady and Brown 2004), the uniaxial compressive strength, Young's modulus, Poisson's ratio, cohesion, and friction angle of the rock are needed to analyze the fracturing and caving process of key strata in overburden strata and the distribution law of abutment stress over key strata and immediate roof in this study. Uniaxial compression 
Table 1 Physical and mechanical properties of coal and surrounding rocks

\begin{tabular}{lllllll}
\hline No. & Formation & $\begin{array}{l}\text { Young's modulus } \\
(\mathrm{GPa})\end{array}$ & $\begin{array}{l}\text { UCS } \\
(\mathrm{MPa})\end{array}$ & $\begin{array}{l}\text { Density } \\
\left(\times 10^{3} \mathrm{~kg} \mathrm{~m}^{3}\right)\end{array}$ & $\begin{array}{l}\text { Angle of internal } \\
\text { friction }\left({ }^{\circ}\right)\end{array}$ & $\begin{array}{l}\text { Thickness } \\
(\mathrm{m})\end{array}$ \\
\hline 1 & Surface layer & 2 & 10 & 1.8 & 45 & 50 \\
2 & Rock layer 1 & 8 & 30 & 2.1 & 45 & 33 \\
3 & Rock layer 2 & 8 & 30 & 2.1 & 25 & 36 \\
4 & Rock layer 3 & 8 & 30 & 2.1 & 22.2 & 31 \\
5 & Key stratum 1 & 15 & 60 & 2.4 & 43 & 5 \\
6 & Rock layer 4 & 8 & 30 & 2.1 & 28 & 10 \\
7 & Key stratum 2 & 15 & 60 & 2.4 & 28 & 5 \\
8 & Immediate roof & 7 & 20 & 2.0 & 28 & 5 \\
9 & Coal seam & 5 & 15 & 1.4 & 28 & 5 \\
10 & Floor & 8 & 60 & 2.4 & 25 & 45 \\
\hline
\end{tabular}

tests were used to determine the uniaxial compressive strength, Young's modulus, and Poisson's ratio. The cohesion and friction angle of the surrounding rocks were obtained by triaxial compression tests. Based on the results of these tests, the panel stratigraphy and other important geotechnical parameters of the coal seam, roof, and floor strata adopted in the simulation for the numerical model are listed in Table 1. Here some rock layers are either grouped into a composite layer or simply taken as a unit rock layer, depending upon the nature, thickness, physico-mechanical properties of rock. The boundary conditions of the numerical model are that the both sides of the model are restricted by displacement in the horizontal direction, the upper of the model is free and the bottom of the model is fixed by displacement. In the simulations, coal mining in ten steps by $5 \mathrm{~m}$ per step was consecutively carried out to simulate the progressive coal extraction process.

\section{Modeling results and discussion}

\subsection{Abutment stress distribution above key strata}

The typical fracturing and caving process and shear stress distribution in overlying strata are presented in Fig. 4 with mining. Only six snapshots are illustrated in Fig. 4 for the limit of the space. Note that the more bright the grayness, the higher the shear stress is, and vice versa in Fig. 4. It can be seen from Fig. 4 that immediate roof bends with coal mining due to gravity after opening cut, and to a certain extent ruptures along the end of coal sidewall. Immediate roof collapses when coal face advances to $20 \mathrm{~m}$ as shown in Fig. $4 \mathrm{a}$. Later on, periodic collapse of immediate roof occurs at an interval with the advance of coal face as demonstrated in Fig. 4b, c. When coal face advances to $60 \mathrm{~m}$, the weak rock strata between key strata 1 and 2 bends with the bending of key stratum 1 and bed separation generates in the middle, but still in close contact with two ends of key stratum 1. Meanwhile, tensile cracks occur in the middle of the strata above key stratum 2 and clusters of mining induced cracks are generated above coal sidewall as shown in Fig. 2c. With the moving forward of coal face, key stratum 1 first ruptures under the action of separated rock, followed by the rupture and collapse of key stratum 2 and the overburden strata due to loss of the support from two ends of rock mass below, as shown in Fig. 4e, f.

The stress distribution curves above key strata 1 and 2 with mining are respectively shown in Figs. 5 and 6. As can be seen from Figs. 4d, d', 5 and 6, the cracks in the strata above key strata 2 are caused by the mininginduced stress concentration. After the mining excavation, the redistribution of stress, characterizing with high stress zone and low stress zone, is generated in the strata above key strata. The stress concentration behind the mined-out area is less than that above coal face since the rock strata behind the mined-out area are in the a constant mining state, resulting in stress concentration, stress transfer and stress re-concentration. As can be seen from Figs. 4 and 5, the stress level above the key strata is small when the mining 
Fig. 4 Fracturing process and stress distribution. Left elastic modulus, right shear stress
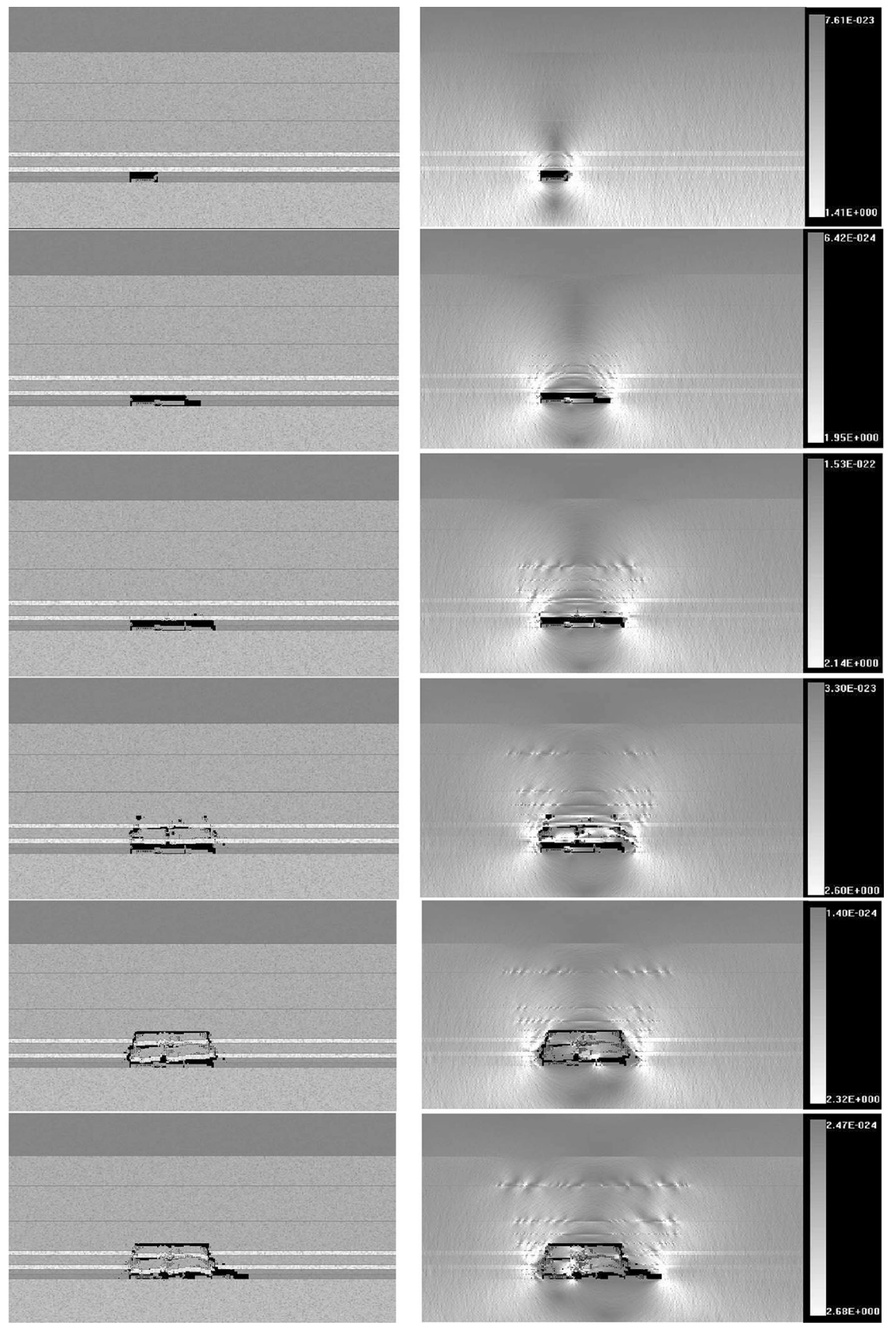

excavation spacing is small, as shown in the excavation spacing of $20 \mathrm{~m}$, the key strata above the minedout area is less stressed due to the formation of selfsupporting role of key strata, and the stress concentration in the strata just above coal sidewall is also not serious. Nevertheless, when the mining excavation spacing increases to $50 \mathrm{~m}$, the stress concentration in the key strata above the coal side walls is serious and obvious stress reduction happens in the mined-out area, moreover, with the continuation of coal mining, the stress in key strata is in a dynamic state, that is, the stress concentration zone in the key strata above coal 


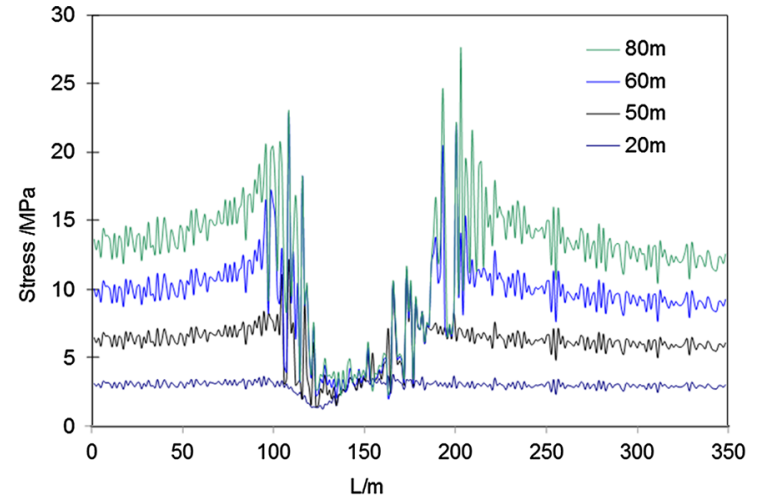

Fig. 5 Abutment stress in key stratum 2 with mining

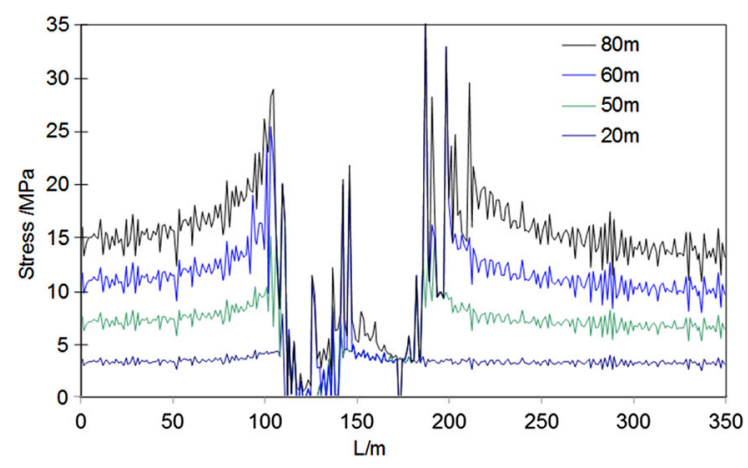

Fig. 6 Abutment stress in key stratum 1 with mining

sidewall gradually moves forward and the stress decrease zone behind mined-out area is gradually expanding as mining. After the breaking of key strata, the broken key strata in mined-out area are only stressed from the gravity of collapsed rock above the key strata, as illustrated in the stress increase in Figs. 4 and 5 and also demonstrated in the stress diagram in Fig. 3. The peak abutment stress in the key strata above coal face is $2.0-2.5$ times the average stress, viz. in situ stress, while the peak abutment stress in the key strata behind mined-out area is about 1.5-1.8 times the average stress, which is in a good agreement with the findings (Qian et al. 2003).

\subsection{Abutment stress distribution in immediate roof}

The distribution of abutment stress in the immediate roof is shown in Fig. 7. As shown in Fig. 7, the position of abutment stress acting on coal pillar at the rear mined-out area remains almost unchanged, while

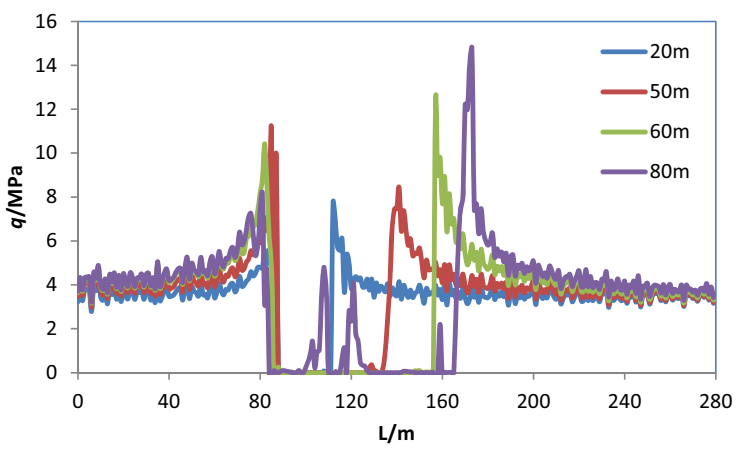

Fig. 7 Abutment stress over immediate roof

Table 2 Relationship between the distance of peak abutment pressure from coal face and mining distance

\begin{tabular}{ll}
\hline Mining distance $(\mathrm{m})$ & $\begin{array}{l}\text { Distance of peak abutment } \\
\text { stress from coalface }(\mathrm{m})\end{array}$ \\
\hline 20 & 3 \\
50 & 7 \\
60 & 8 \\
80 & 6 \\
\hline
\end{tabular}

its peak continue to increase with the advance of the coal face. As the key strata ruptures and collapses, the peak abutment stress remains almost unchanged and forms a constant abutment stress with the advance of coal face. The abutment stress in front of coal face continues to move forward and forms moving abutment stress. The relationship between the distance of peak abutment stress from coal face and mining distance is presented in Table 2 . As can be clearly seen from Table 2, the distance of peak abutment stress from coal face is less than $10 \mathrm{~m}$ in the operation of coal mining, which agrees well with the findings (Qian and Shi 2003).

\subsection{Effect of key strata rupturing on abutment stress}

As mentioned earlier, when the face advances to $60 \mathrm{~m}$, the key strata 1 and 2 both collapse. The abutment stress in the coal sidewall in front of coal face at the pre-rupturing, rupturing and post-rupturing of key later is shown in Fig. 8. As can be seen from Fig. 8, the abutment stress in the coal rib gradually increases before the rupturing of key strata and reaches to the maximum at the rupturing of key strata. After the 


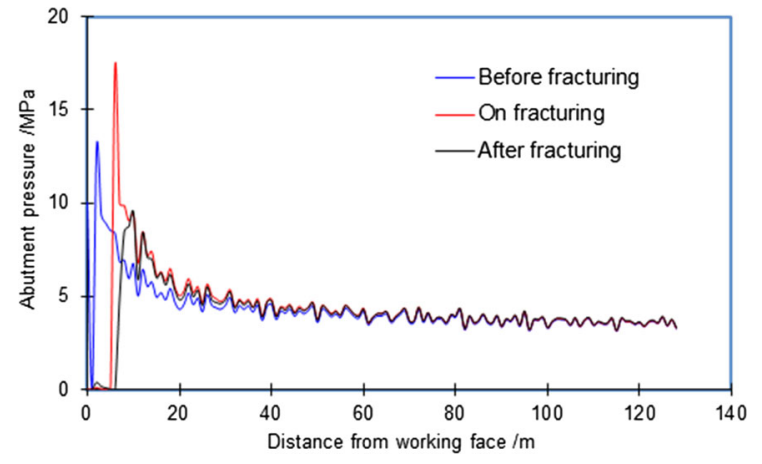

Fig. 8 Distribution of abutment stress in coal rib before, at and after the fracture of key strata

rupturing of the key strata, the abutment stress in front of the coal sidewall is greatly reduced, and the peak abutment stress continuously moves away from coalface and toward coal seam. The reason for this is that the key strata bears most of the abutment stress before the rupturing of key strata, but after the rupturing of key strata, the stress redistributes and this part of the load passed on coal and coal yields and fails due to low strength under higher stress concentration, and thus the abutment stress acting on coal shifts inwards the coal.

\subsection{Effect of key strata rupturing on surface subsidence}

The relationship between vertical displacement and horizontal displacement of earth surface in coal mining from open cut to the rupturing of key strata is shown in Fig. 9. Since the horizontal displacement of the numerical model at the left and right boundary is kept fixed and only the vertical displacements are allowed in the model to investigate the strata movement with mining, the vertical displacement can be seen in a form of surface subsidence, and the horizontal displacement is equal to zero at the left and right boundary of the model domain. While the left part of the strata in the model domain moves to the right and the right part of the strata in the model moves to the left. Thus, we can see that there are some positive displacements towards the right direction as well as negative displacements towards the left direction since they move in opposite direction. As can be seen from Fig. 9, the impact of coal mining on horizontal and vertical displacement is small when the
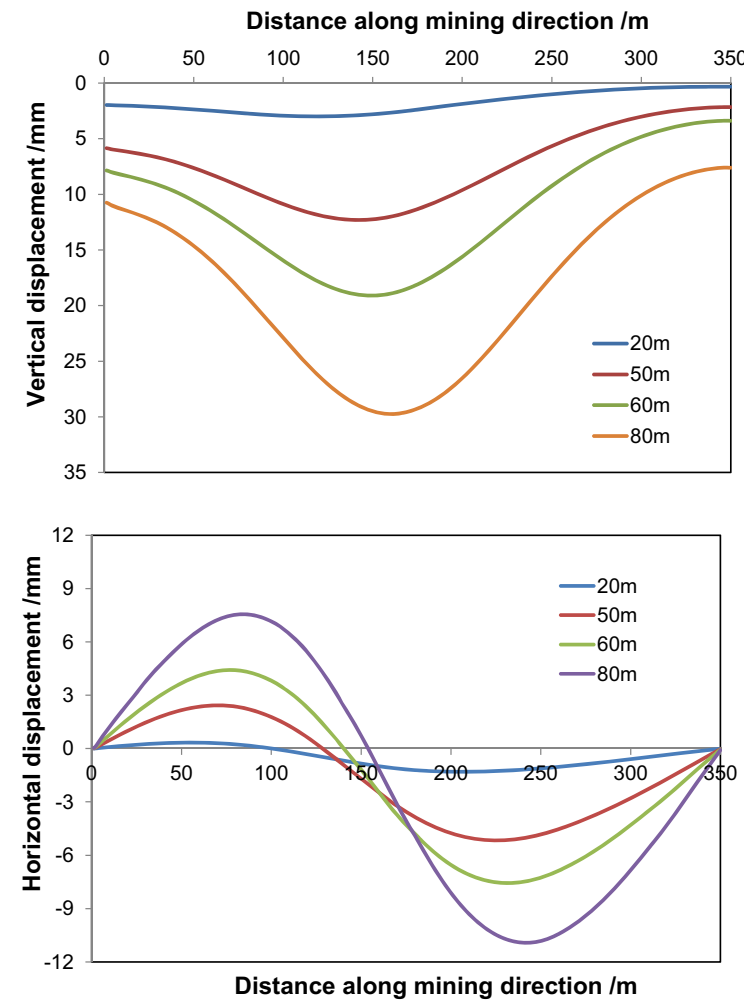

Fig. 9 Vertical and horizontal displacement of earth surface with mining

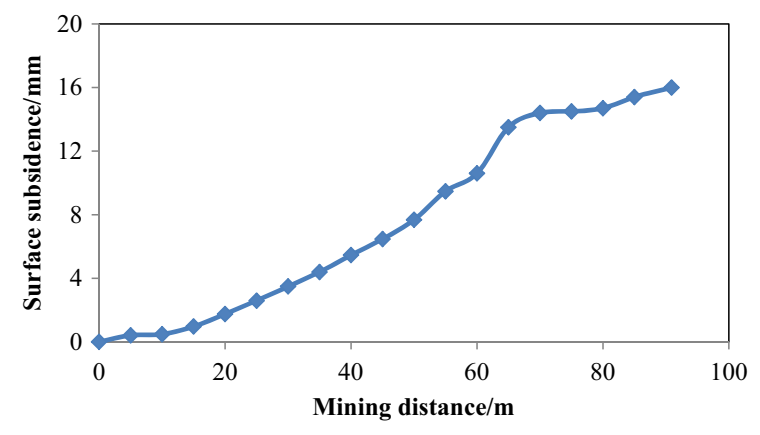

Fig. 10 Surface subsidence as mining

face advance distance is small, and the vertical displacement profile of earth surface is not symmetrical. With the increase in mining distance of coal face, the movement (vertical displacement) and the horizontal movement (horizontal displacement) of surface subsidence are also increased with a trend of gradually symmetrical distribution, characterizing with a surface subsidence basin. In addition, the rupturing of key strata has a greater impact on earth surface subsidence in the process of coal extraction as shown in Fig. 10. 
Before the breaking of the key strata, vertical surface subsidence gradually increased and the subsidence rate is maintained substantially constant as demonstrated in the first part of curve in Fig. 10. After the breaking of the key strata, i.e., at the $60 \mathrm{~m}$ distance of the coal face mining, earth surface subsidence rate increased dramatically, later on, the rate of surface subsidence again gradually stabilized with the proceeding of coal mining operation.

\section{Conclusions}

In this paper, numerical simulations on the fracturing and caving of overburden strata induced by longwall mining were performed to study the deformation and failure characteristics of overlying strata and associated abutment stress distribution in strata using rock failure process analysis code, which considers the heterogeneity and nonlinear characteristics of overburden rock strata. Numerical results show that the equilibrium of stress in rock mass was disturbed due to coal mining and that the stress around the coal extraction panel is redistributed. The stress above key layers is characterized with low stress zone, high stress zone and in situ stress zone along the mining direction. The peak abutment stress in key layer over the coal face is 2.0-2.5 times the in situ stress and the peak abutment stress in key layer behind the mined-out area is 1.5-1.8 times the in situ stress. After coal mining, the peak abutment stress in front of coal face is generally higher than the stable peak abutment stress around the mined-out area. The distance of the peak abutment stress in front of coal face away from the coal face sidewall is approximately $10 \mathrm{~m}$. The abutment stress in front of coal face gradually increases with coal mining before the rupture of key layer and reaches to the maximum at the rupture of key layer. After the rupture of key layer, the abutment stress in front of coal face sharply decreases and the peak abutment stress continuously shifts to the coal seam. The rupture of key layers has a greater impact on earth surface subsidence in the process of coal mining. Before the breaking of key layer, the rate of earth surface subsidence basically remains stable, while the rate of earth surface subsidence increases dramatically after the breaking of key layer and gradually tends to be stabilized with mining excavation. The approach employed in this paper captures the mining-induced deformation and failure characteristics of overlying strata and associated abutment stress distribution in strata, which is in agreement with field observations. It is reasonably indicated that rock failure process analysis code can be effectively applied in the study of strata movement and surface subsidence induced by mining excavation.

Acknowledgments The joint support provided by the National Basic Research Program of China (2013CB227900) and National Natural Science Foundation of China (Grant Nos. 41172265 and 51474051) and Fundamental Research Funds for the Central Universities (N130501002, N130401005)is highly acknowledged.

\section{References}

Brady BHG, Brown ET (2004) Rock mechanics for underground mining. Kluwer Academic Publishers, London

Chen H, Cheng Y, Ren T, Zhou H, Liu Q (2014) Permeability distribution characteristics of protected coal seams during unloading of the coal body. Int $\mathrm{J}$ Rock Mech Min Sci 71:105-116

Chugh YP, Pula O, Pytel WM (1990) Ultimate bearing capacity and settlement of coal pillar sub-strata. Int J Min Geol Engg 8:111-130

Hammy KY, Fejes AJ (1992) Characterization of overburden response to long wall mining in the western United States. In: Proceedings of eleventh international conference on ground control in mining. The University of Wollongong, NSW, pp 334-344

Holla L (1997) Ground movement due to longwall mining in high relief areas in New South Wales, Australia. Int J Rock Mech Min Sci 34:775-787

Holla L, Buizen M (1991a) The ground movement, strata fracturing and changes in permeability due to deep longwall mining. Int $\mathbf{J}$ Rock Mech Min Sci Geomech Abstr 28:207-217

Holla L, Buizen M (1991b) The ground movement, strata fracturing and changes in permeability due to deep longwall mining. Int J Rock Mech Min Sci Geomech Abstr 28:207-217

Hosseini N, Oraee K, Shahriar K, Goshtasbi K (2013) Studying the stress redistribution around the longwall mining panel using passive seismic velocity tomography and geostatistical estimation. Arab J Geosci 6:1407-1416

Islam MdR, Hayashi D, Kamruzzaman ABM (2009) Finite element modeling of stress distributions and problems for multi-slice longwall mining in Bangladesh, with special reference to the Barapukuria coal mine. Int J Coal Geol 78:91-109

Jeager JC, Cook NGW, Zimmerman R (2007) Fundamentals of rock mechanics, 4 th edn. Wiley-Blackwell, Singapore

Ju J, Xu J (2013) Structural characteristics of key strata and strata behaviour of a fully mechanized longwall face with 7.0 m height chocks. Int J Rock Mech Min Sci 58:46-54

Lemaitre J, Desmorat R (2005) Engineering damage mechanics. Springer, Berlin 
Li LC, Tang CA, Zhao XD, Cai M (2014) Block caving-induced strata movement and associated surface subsidence: a numerical study based on a demonstration model. Bull Eng Geol Environ 73:1165-1182

Noorian-Bidgoli M, Jing L (2015) Stochastic analysis of strength and deformability of fractured rocks using multifracture system realizations. Int J Rock Mech Min Sci 78:108-117

Qian MG, Shi PW (2003) Ground pressure and strata control. China University of Mining and Technology Press, Xuzhou

Qian MG, Miao XX, Xu JL, Mao XB (2003) Key strata theory in ground control. China University of Mining and Technology Press, Xuzhou China (in Chinese)

Shibata S, Zarlin N, Shimada H, Hamanaka A, Sasaoka T, Matsui K, Laowattanabandit P (2014) Preliminary study on design of longwall mining from final highwall at Mae Moh Lignite Mine in Thailand. In: Drebenstedt C, Singhal R (eds) Mine planning and equipment selection. Springer International Publishing, Switzerland, pp 227-234

Suchowerska AM, Merifield RS, Carter JP (2013) Vertical stress changes in multi-seam mining under supercritical longwall panels. Int J Rock Mech Min Sci 61:306-320

Tang CA, Zhang YB, Liang ZZ, Xu T, Tham LG, Lindqvist PA, Kou SQ, Liu HY (2006) Fracture spacing in layered materials and pattern transition from parallel to polygonal fractures. Phys Rev E 73:0561201-0561209

Wang H, Jiang Y, Zhao Y, Zhu J, Liu S (2013) Numerical investigation of the dynamic mechanical state of a coal pillar during longwall mining panel extraction. Rock Mech Rock Eng 46:1211-1221

Wasantha PLP, Ranjith PG, Zhang QB, Xu T (2015) Do joint geometrical properties influence the fracturing behaviour of jointed rock? An investigation through joint orientation. Geomech Geophys Geo Energy Geo Resour 1:3-14
Weibull W (1951) A statistical distribution function of wide applicability. J Appl Mech 18:293-297

Xie J, Gao M, Yu B, Zhang R, Jin W (2015) Coal permeability model on the effect of gas extraction within effective influence zone. Geomech Geophys Geo Energy Geo Resour 1:15-27

Xu T, Tang CA, Yang TH, Zhu WC, Liu JS (2006) Numerical investigation of coal and gas outbursts in underground collieries. Int J Rock Mech Min Sci 43:905-919

Xu T, Tang CA, Zhao J, Li LC, Heap MJ (2012) Modelling the time-dependent rheological behaviour of heterogeneous brittle rocks. Geophys J Int 189:1781-1796

Xu T, Ranjith PG, Wasantha PLP, Zhao J, Tang CA, Zhu WC (2013) Influence of the geometry of partially-spanning joints on mechanical properties of rock in uniaxial compression. Eng Geol 167:134-147

Xu T, Xu Q, Deng M, Ma T, Yang T, Tang C-a (2014) A numerical analysis of rock creep-induced slide: a case study from Jiweishan Mountain, China. Environ Earth Sci 72:2111-2128

Yakovlev G, Gran JD, Turcotte DL, Rundle JB, Holliday JR, Klein W (2010) A damage-mechanics model for fracture nucleation and propagation. Theoret Appl Fract Mech 53:180-184

Yang ZL (2010) Stability of nearly horizontal roof strata in shallow seam longwall mining. Int J Rock Mech Min Sci 47:672-677

Yang TH, Xu T, Liu HY, Tang CA, Shi BM, Yu QX (2011a) Stress-damage-flow coupling model and its application to pressure relief coal bed methane in deep coal seam. Int $\mathbf{J}$ Coal Geol 86:357-366

Yang W, Lin B-q Qu, Y-a Li Z-w, Zhai C, L-1 Jia, W-q Zhao (2011b) Stress evolution with time and space during mining of a coal seam. Int J Rock Mech Min Sci 48:1145-1152 